\title{
Education level as a predictor of survival in patients with multiple myeloma
}

\author{
Limei Xu' , Xiuju Wang ${ }^{2}$, Xueyi Pan ${ }^{3}$, Xiaotao Wang ${ }^{4}$, Qing Wang ${ }^{5}$, Bingyi Wu ${ }^{6}$, Jiahui Cai ${ }^{6}$, Ying Zhao ${ }^{7}$, \\ Lijuan Chen ${ }^{8}$, Wuping $\mathrm{Li}^{9}$ and Juan $\mathrm{Li}^{i^{*}}$
}

\begin{abstract}
Background: Disparities in multiple myeloma (MM) prognosis based on sociodemographic factors may exist. We investigated whether education level at diagnosis influenced Chinese MM patient outcomes.

Methods: We performed a multicenter retrospective analysis of data from 773 MM patients across 9 centers in China from 2006 to 2019. Sociodemographic and clinical factors at diagnosis and treatment regimens were recorded, and univariate and multivariate analyses were performed.

Results: Overall, $69.2 \%$ of patients had low education levels. Patients with low education levels differed from those with high education levels in that they were more likely to be older, and a higher proportion lived in rural areas, were unemployed, had lower annual incomes and lacked insurance. Additionally, compared to patients with high education levels, patients with low education levels had a higher proportion of international staging system (ISS) stage III classification and elevated lactate dehydrogenase (LDH) levels and underwent transplantation less often. Patients with high education levels had a median progression-free survival (PFS) of 67.50 (95\% confidence interval (Cl): 51.66-83.39) months, which was better than that of patients with low education levels (30.60 months, $95 \%$ Cl: 27.38-33.82, $p<0.001$ ). Similarly, patients with high education levels had a median overall survival (OS) of 122.27 (95\% Cl: 117.05-127.49) months, which was also better than that of patients with low education levels (58.83 months, 95\% Cl: 48.87-62.79, $p<0.001$ ). In the multivariable analysis, patients with high education levels had lower relapse rates and higher survival rates than did those with low education level in terms of PFS and OS (hazard ratio $(H R)=0.50$ [95\% Cl: 0.34-0.72], $p<0.001 ; H R=0.32$ [0.19-0.56], $p<0.001$, respectively).
\end{abstract}

Conclusions: Low education levels may independently predict poor survival in MM patients in China.

Keywords: Education level, Sociodemographic status, Multiple myeloma, Survival prognosis

\section{Background}

Multiple myeloma (MM) is characterized by the clonal proliferation of malignant plasma cells, causing lytic skeletal lesions, renal failure, hypercalcemia, and anemia, and patients typically present with monoclonal protein in the serum and/or urine $[1,2]$. Currently, $M M$ is the second-most common malignancy of the blood in many

\footnotetext{
* Correspondence: juanlihematology@163.com

'Department of Hematology, The First Affiliated Hospital of Sun Yat-sen University, Guangzhou, Guangdong, China

Full list of author information is available at the end of the article
}

countries and has been estimated to account for $1.82 \%$ of all malignancies and $18 \%$ of all hematological malignancies, according to data from the United States [3, 4].

In recent years, with the continuous advent of new drugs and new treatments, the prognosis of patients with MM has been greatly improved. However, not all MM patients benefit equally from these improvements [5]. To explore the causes of this difference, a few studies from the Cancer Registry and the SEER database have shown the impact of racial and socioeconomic status (SES) disparities on the prognosis of patients with

(c) The Author(s). 2020 Open Access This article is licensed under a Creative Commons Attribution 4.0 International License, which permits use, sharing, adaptation, distribution and reproduction in any medium or format, as long as you give appropriate credit to the original author(s) and the source, provide a link to the Creative Commons licence, and indicate if changes were made. The images or other third party material in this article are included in the article's Creative Commons licence, unless indicated otherwise in a credit line to the material. If material is not included in the article's Creative Commons licence and your intended use is not permitted by statutory regulation or exceeds the permitted use, you will need to obtain permission directly from the copyright holder. To view a copy of this licence, visit http://creativecommons.org/licenses/by/4.0/ The Creative Commons Public Domain Dedication waiver (http://creativecommons.org/publicdomain/zero/1.0/) applies to the data made available in this article, unless otherwise stated in a credit line to the data. 
multiple myeloma [6-10]. Some studies have reported a significant increase in the risk of MM in individuals with low SES [8-10]. In addition, some studies reported differences in the clinical characteristics, incidence and survival prognosis among patients with MM across racial and ethnic groups [6], while some studies showed no consistent association between race/ethnicity or SES and survival outcomes after adjustment for confounders [7, 11, 12].

Globally, compared with the United States and other high-income countries, low- or middle-income countries have slower regulatory approval of drugs, fewer types of drugs available, and higher drug prices when adjusted for gross domestic product per capita; thus, the chances of effective treatment for these MM patients are greatly reduced [13, 14]. However, the mortality of MM in China, a country with a large population, has increased in recent years, especially in rural areas [15]. The impact of demographic and socioeconomic factors on the prognosis and survival of patients with MM has not been reported in developing countries such as China.

Education level is an important factor in patients' demography. To understand the relationship between the education level and survival prognosis of Chinese MM patients, demographic factors (e.g., education level, occupational status, income, place of residence, marital status) and clinical characteristics (e.g., initial disease staging, lactate dehydrogenase (LDH) level, cytogenetics, comorbidities) at diagnosis and treatment regimens (e.g., underwent transplantation) were recorded and analyzed.

\section{Methods}

\section{Patients}

This retrospective, multicenter study was conducted in 9 centers across several provinces in China. A total of 773 newly diagnosed $\mathrm{MM}$ patients were enrolled in this study from January 2006 to July 2019 at each of the participating institutions. In accordance with the diagnostic criteria for multiple myeloma and disease progression, eligible patients were defined according to standard International Myeloma Working Group criteria [16, 17]. The treatment of patients was divided into transplantation and nontransplantation. Progression-free survival (PFS) was calculated from the time of the initial diagnosis of MM to disease progression, death or the last follow-up, and overall survival (OS) was calculated from the time of the initial diagnosis of MM until death or the last follow-u.

\section{Sociodemographic and clinical variables}

We analyzed the personal information and clinical information of each patient at the time of the first visit, including age, sex, smoking status (yes or no), marital status (married, single, divorced or widowed), place of residence (urban or rural), the distance between place of residence and the hospital (in the same or different provinces), insurance status (insured or uninsured), and annual household income $(<\$ 42,500$ USD, $\geq \$ 42,500$ USD). As it costs approximately $\$ 42,500$ USD to receive regular induced chemotherapy for 4 cycles and subsequent autologous stem cell transplantation (ASCT) for MM patients, we set $\$ 42,500$ USD as the cut-off for annual household income. The education level was divided into two classes based on records of formal schooling: secondary school or lower was defined as a low education level, and a bachelor's degree or higher was defined as a high education level. Occupational status was divided into employed and unemployed.

Clinical data included initial symptoms, comorbidity at the time of MM diagnosis, time from the onset of symptoms to diagnosis ( $<1$ month, $\geq 1$ month), international staging system (ISS) stage (I, II, III), LDH level, and cytogenetic abnormality by fluorescence in situ hybridization (FISH). Briefly, translocation 4;14 [t $(4 ; 14)]$ and/or del $[17 \mathrm{p}]$ and/or $\mathrm{t}[14 ; 16]$ determined by FISH was defined as high risk cytogenetics; not carrying these mutations was defined as a standard risk cytogenetics [18]. The treatment includes whether to transplant or not. Treatment compliance was expressed by whether patients underwent regular treatment or not. The initial symptoms included bone pain, anemia, infection, anesthesia, and renal insufficiency.

\section{Statistical analysis}

SPSS Statistics version 23 was utilized for statistical analysis. Patient baseline characteristics were analyzed using Student's t-test or the chi-square test. The Kaplan-Meier method was performed for survival analysis, and differences were analyzed using the log-rank test. Univariate and multivariate analyses of features predicting survival were examined using hazard ratios (HRs) and corresponding 95\% confidence intervals (95\% CIs) calculated from Cox proportional hazards models. $p<0.05$ was considered to be statistically significant.

\section{Results \\ Baseline demographic and clinical characteristics of the MM patients}

The main demographic, socioeconomic, and clinical features of the patients are listed in Table 1. Our cohort included 773 patients: $56.9 \%$ were male, $53.3 \%$ were under the age of 60 , and $28.2 \%$ had a history of smoking. Most patients were married (96.0\%), and most lived in the same province as their treating hospital and in urban areas (86.4 and $71.4 \%$ ). Additionally, $69.2 \%$ of patients had low education levels, and only $18.6 \%$ were still employed during treatment. A total of $77.0 \%$ of patients had lower incomes ( $\leq \$ 42,500$ USD), and no insurance was listed for $69.3 \%$ of patients. The initial symptoms of the patients were mainly bone pain, followed by anemia 
Table 1 Characteristics of the patients with multiple myeloma

\begin{tabular}{|c|}
\hline Variables \\
\hline Sex \\
\hline Male \\
\hline Female \\
\hline Age \\
\hline$<60$ \\
\hline$\geq 60$ \\
\hline Smoking \\
\hline Yes \\
\hline No \\
\hline Marital status \\
\hline Married \\
\hline Unmarried \\
\hline Divorced \\
\hline Widowed \\
\hline Residential area \\
\hline Urban \\
\hline Rural \\
\hline Distance to hospital \\
\hline In the same province \\
\hline In a different province \\
\hline Education level \\
\hline Low education level \\
\hline High education level \\
\hline Unknown \\
\hline Occupational status \\
\hline Employed \\
\hline Unemployed \\
\hline Unknown \\
\hline
\end{tabular}

\section{Average annual income}

$\leq \$ 42,500$ USD

$>\$ 42,500$ USD

Unknown

Insurance status

Any insurance

No insurance

Unknown

Initial symptoms

Bone pain

Anemia

Infection

Anesthesia

Renal insufficiency

Others

$\mathrm{N}(\%)$

$9(1.2)$

$13(1.7)$

$9(1.1)$

$24(3.1)$

$61(7.9)$

$63(8.2)$

$34(4.4)$

$11(1.4)$

$47(6.1)$

$55(7.1)$
Table 1 Characteristics of the patients with multiple myeloma (Continued)

440 (56.9)

$333(43.1)$

$412(53.3)$

$361(46.7)$

$218(28.2)$

$555(71.8)$

$>1$ month

$592(76.6)$

ISS stage

$742(96.0)$

I/II

$531(68.7)$

III

$226(29.2)$

Unknown

$16(2.1)$

LDH level

$<240 \mathrm{U} / \mathrm{L}$

$565(73.1)$

$552(71.4)$

$\geq 240 \mathrm{U} / \mathrm{L}$

144 (18.6)

Unknown

$64(8.3)$

Cytogenetic abnormality by FISH

$668(86.4)$

High risk

136 (17.6)

Standard risk

$429(55.5)$

Unknown

$208(26.9)$

Receipt of transplant

Yes

$283(36.6)$

No

$490(63.4)$

Regular treatment

$144(18.6)$

Yes

$524(67.8)$

605 (78.3)

$595(77.0)$

$117(15.1)$

$174(22.5)$

$536(69.3)$

$508(65.7)$

$118(15.3)$
No

$249(32.2)$

ISS international staging system, $L D H$ lactate dehydrogenase, FISH fluorescence in situ hybridization

and renal function impairment. Additionally, 38.5\% of patients had cardiovascular disease and/or metabolic syndrome, and $4.7 \%$ had other tumors. The time from onset to definite diagnosis varied with most of the patients receiving a definite diagnosis after more than 1 month (76.6\%), and $29.2 \%$ of the patients had ISS stage III disease at the time of onset. A total of $18.6 \%$ of the patients had LDH levels greater than $240 \mathrm{U} / \mathrm{L}$, and $17.6 \%$ of the patients had high-risk cytogenetics. Moreover, $36.6 \%$ of patients underwent transplantation and $67.8 \%$ of the patients received regular treatment and underwent regular follow-up.

\section{Comparison between MM patients with a high vs low education level}

Information on education level was available for $98.5 \%$ of the patients (761/773). Patients with low education 
levels were more likely to be older ( $\geq 60$ years, $51.2 \%$ vs $36.3 \%, p<0.001)$, and a higher proportion were female (46.9\% vs $35.0 \%, p=0.002)$, lived in rural areas $(39.1 \%$ vs $5.3 \%, p<0.001)$, were unemployed $(86.9 \%$ vs $66.2 \%, p<$ $0.001)$, had a lower income (94.5\% vs $59.3 \%, p<0.001)$, lacked insurance $(82.2 \%$ vs $60.4 \%, p<0.001)$ and had comorbidities (32.3\% vs $43.8 \%, p=0.003)$. Additionally, time to diagnosis $>1$ month was more frequent in patients with low education levels $(81.3 \%$ vs $65.0 \%, p<$ 0.001 ), and they consistently had a higher ISS stage (III, $32.5 \%$ vs $23.7 \%, p=0.014$ ) and elevations in LDH levels ( $\geq 240 \mathrm{U} / \mathrm{L}, 23.1 \%$ vs $13.0 \%, p=0.003$ ). However, there was no difference in cytogenetics between the two groups. In addition, patients with high education levels were more likely to be treated via transplantation $(59.3 \%$ vs $27.9 \%, p<0.001)$ and undergo regular treatment $(87.6 \%$ vs $60.7 \%, p<0.001)$ than patients with low education levels (Table 2).

\section{Univariate analyses for PFS and OS}

The median follow-up for the entire cohort was 29.6 months (range, 0.3 months to 162.8 months) from the start of diagnosis. Kaplan-Meier analyses showed that the median PFS and OS for all patients were, respectively, 39.93(95\% CI: 35.79-44.07) months and 79.63 (95\% CI: 58.88-100.48) months (Fig. 1a, b). Patients with high education levels had a median PFS of 67.50 (95\% CI: 51.66-83.39) months, which was better than that of patients with low education levels (30.60 months, 95\% CI: 27.38-33.82, $p<0.001$, Fig. 1c). Similarly, patients with high education levels had a median OS of 122.27 (95\% CI: 117.05-127.49) months, which was also better than that of patients with low education levels (58.83 months, 95\% CI: 48.87-62.79, $p<0.001$, Fig. 1d).

In this study, univariate Cox regression analyses were performed to explore the association between the baseline factors of patients and PFS and OS. The sociodemographic factors associated with worse PFS and OS in the univariate Cox regression model included age $(\mathrm{HR}=1.04$ [95\% CI: $1.02-1.04]$; $\mathrm{HR}=1.03$ [95\% CI: $1.02-1.05]$, respectively), residence in a rural setting $(\mathrm{HR}=1.48[95 \%$ CI: $1.14-1.93]$; $\mathrm{HR}=1.47[95 \% \mathrm{CI}: 1.06-2.05]$, respectively), living in a different province from the treating hospital $(\mathrm{HR}=1.18[95 \% \mathrm{CI}: 1.01-1.37] ; \mathrm{HR}=1.15[95 \%$ CI: 0.94-1.41], respectively), being unemployed ( $\mathrm{HR}=$ 1.67[1.22-2.30]; $\mathrm{HR}=2.53[1.55-4.13]$, respectively), and a lack of insurance $(\mathrm{HR}=1.54[95 \% \mathrm{CI}$ : $1.15-2.06] ; \mathrm{HR}=$ 2.16[95\% CI: 1.43-3.29], respectively). Additional clinical factors associated with worse PFS and OS included complications at diagnosis $(\mathrm{HR}=1.72[95 \% \mathrm{CI}: 1.35-2.18]$; $\mathrm{HR}=2.54[95 \% \mathrm{CI}: 1.81-3.56]$, respectively), time to diagnosis > 1 month (HR $=1.47[95 \% \mathrm{CI}: 1.13-1.91]$; $\mathrm{HR}=$ 1.96[95\% CI: $1.37-2.81]$, respectively), ISS stage III disease $(\mathrm{HR}=1.23[95 \% \mathrm{CI}: 1.09-1.39] ; \mathrm{HR}=1.38[95 \% \mathrm{CI}$ :
1.19-1.60], respectively), elevations in LDH levels $(\mathrm{HR}=$ 1.87[95\% CI: 1.43-2.46]; HR $=1.85$ [95\% CI: $1.32-2.60$ ], respectively), high-risk cytogenetics $(\mathrm{HR}=1.68[95 \% \mathrm{CI}$ : $1.26-2.25] ; \mathrm{HR}=1.98$ [95\% CI: 1.38-2.82], respectively), no transplantation $(\mathrm{HR}=2.98$ [95\% CI: $2.34-3.80]$; $\mathrm{HR}=$ 2.53[95\% CI: 1.87-3.44], respectively), and irregular treatment $(\mathrm{HR}=3.28[95 \% \mathrm{CI}: 2.59-4.16] ; \mathrm{HR}=3.51[95 \%$ CI: 2.61-4.71], respectively). In addition, sociodemographic factors associated with better PFS and OS in the univariate Cox regression model included a high education level $(\mathrm{HR}=0.39[95 \% \mathrm{CI}: 0.30-0.52] ; \mathrm{HR}=0.25[95 \%$ CI: $0.17-0.38]$, respectively) and a high annual income (i.e., $\geq \$ 42,500 ; \mathrm{HR}=0.51[95 \%$ CI: $0.37-0.70] ; \mathrm{HR}=$ 0.36[95\% CI: 0.23-0.55], respectively) (Table 3).

\section{Multivariate analyses for PFS and OS}

To further analyze the influence of sociodemographic factors on patient survival, multivariate Cox regression analyses were conducted. Since age is an important factor affecting survival and we found that education and age have interactive effects on survival, we analyzed the effects of demographic and clinical factors on PFS and OS in patients with MM by dividing them into groups of patients $<60$ years old and $\geq 60$ years old.

We found that in different age groups, education level, LDH levels, cytogenetics and receipt of transplant were independently associated with PFS, while in the age stratification analysis, regular treatment was an independent factor affecting the PFS of patients $<60$ years old. (Table 4). In addition, for all patients, the independent risk factors affecting OS included patients' age (per year of age), low education level, elevated LDH level, high-risk cytogenetics, complications at diagnosis and irregular treatment. In the analysis of age stratification, for patients younger than 60 years old, education level, cytogenetics and regular treatment were independent prognostic factors for OS. Additionally, for patients $\geq 60$ years old, education level, LDH levels, cytogenetics and complications at diagnosis were independent prognostic factors for OS (Table 5).

\section{Discussion}

To the best of our knowledge, this study is the first to examine the relationship between sociodemographic factors and survival in patients with MM in China. The prognostic factors of MM mainly include host factors, tumor characteristics and treatment methods [19]. A single factor is often not enough to determine the prognosis. Among the tumor factors, we usually evaluate the prognosis of patients by ISS stage, LDH level and cytogenetics. Moreover, in terms of treatment, we also found that hematopoietic stem cell transplantation in patients with MM can significantly improve the survival prognosis [20]. However, there is no consensus on the impact 
Table 2 Comparison of demographic and clinical characteristics between patients with high and low education levels

\begin{tabular}{|c|c|c|c|c|c|}
\hline \multirow[t]{2}{*}{ Variables } & \multicolumn{2}{|c|}{ Low education level } & \multicolumn{2}{|c|}{ High education level } & \multirow[t]{2}{*}{$P$} \\
\hline & $N=535$ & (\%) & $N=226$ & (\%) & \\
\hline Age & & & & & $<0.001$ \\
\hline$<60$ & 261 & 48.8 & 144 & 63.7 & \\
\hline$\geq 60$ & 274 & 51.2 & 82 & 36.3 & \\
\hline Sex & & & & & 0.002 \\
\hline Male & 284 & 53.1 & 147 & 65.0 & \\
\hline Female & 251 & 46.9 & 79 & 35.0 & \\
\hline Smoking & & & & & 0.183 \\
\hline Yes & 158 & 29.5 & 56 & 24.8 & \\
\hline No & 377 & 70.5 & 170 & 75.2 & \\
\hline Marital status & & & & & 0.657 \\
\hline Married & 515 & 96.3 & 216 & 95.6 & \\
\hline Other & 20 & 3.7 & 10 & 4.4 & \\
\hline Residential area & & & & & $<0.001$ \\
\hline Urban & 326 & 60.9 & 214 & 94.7 & \\
\hline Rural & 209 & 39.1 & 12 & 5.3 & \\
\hline Distance to hospital & & & & & 0.287 \\
\hline Same province & 458 & 85.6 & 200 & 88.5 & \\
\hline Different province & 77 & 14.4 & 26 & 11.5 & \\
\hline Occupational status & & & & & $<0.001$ \\
\hline Employed & 68 & 13.1 & 76 & 33.8 & \\
\hline Unemployed & 453 & 86.9 & 149 & 66.2 & \\
\hline Average annual income & & & & & $<0.001$ \\
\hline$<\$ 42,500$ USD & 464 & 94.5 & 131 & 59.3 & \\
\hline$\geq \$ 42,500$ USD & 27 & 5.5 & 90 & 40.7 & \\
\hline Insurance status & & & & & $<0.001$ \\
\hline Any insurance & 88 & 17.8 & 86 & 39.6 & \\
\hline No insurance & 405 & 82.2 & 131 & 60.4 & \\
\hline Comorbidity & & & & & $<0.003$ \\
\hline Yes & 362 & 67.7 & 127 & 56.2 & \\
\hline No & 173 & 32.3 & 99 & 43.8 & \\
\hline Time to diagnosis & & & & & $<0.001$ \\
\hline$\leq 1$ month & 100 & 18.7 & 79 & 35.0 & \\
\hline$>1$ months & 435 & 81.3 & 147 & 65.0 & \\
\hline ISS stage & & & & & 0.014 \\
\hline$|/| \mid$ & 351 & 67.5 & 172 & 76.4 & \\
\hline III & 169 & 32.5 & 53 & 23.6 & \\
\hline \multicolumn{6}{|l|}{ LDH } \\
\hline$\geq 240 \mathrm{U} / \mathrm{L}$ & 115 & 23.1 & 26 & 13.0 & 0.003 \\
\hline$<240 \mathrm{U} / \mathrm{L}$ & 383 & 76.9 & 174 & 87.0 & \\
\hline Cytogenetics & & & & & 0.768 \\
\hline High risk & 96 & 24.5 & 38 & 23.3 & \\
\hline Standard risk & 296 & 75.5 & 125 & 76.7 & \\
\hline
\end{tabular}


Table 2 Comparison of demographic and clinical characteristics between patients with high and low education levels (Continued)

\begin{tabular}{|c|c|c|c|c|c|}
\hline \multirow[t]{2}{*}{ Variables } & \multicolumn{2}{|c|}{ Low education level } & \multicolumn{2}{|c|}{ High education level } & \multirow[t]{2}{*}{$P$} \\
\hline & $N=535$ & $(\%)$ & $N=226$ & $(\%)$ & \\
\hline Receipt of transplant & & & & & $<0.001$ \\
\hline Yes & 149 & 27.9 & 134 & 59.3 & \\
\hline No & 386 & 72.2 & 92 & 40.7 & \\
\hline Regular treatment & & & & & $<0.001$ \\
\hline Yes & 325 & 60.7 & 198 & 87.6 & \\
\hline No & 210 & 39.3 & 28 & 12.4 & \\
\hline
\end{tabular}

ISS international staging system, $L D H$ lactate dehydrogenase

of patient host factors on prognosis. To date, the prognosis of patients has not been evaluated with these three factors at the same time. Therefore, we included demographic factors (e.g., age, sex, education level, income, work, insurance), tumor characteristics (e.g., ISS stage, cytogenetics, LDH level) and treatment methods in the analysis.

SES is often measured by income, education or occupation, either as singular variables or in combination, which is a strong predictor for survival prognoses in $\mathrm{MM}$ as well as other diseases $[6,8,21,22]$. It can be assumed that the education level covaries with SES. Cancer death rates vary considerably by level of education [23]. Attalla, K. et al. found that penile cancer patients with low education levels were more likely to be diagnosed with a worse pathologic T stage [24]. Hwang, K.T. et al. found that high education levels conferred a superior prognosis for breast cancer patients in the subgroup aged $>50$ years; these patients had a lower mean age at the first diagnosis and more favorable biological features [25].

In our study, we set income, education level and occupational status as independent factors. As age and

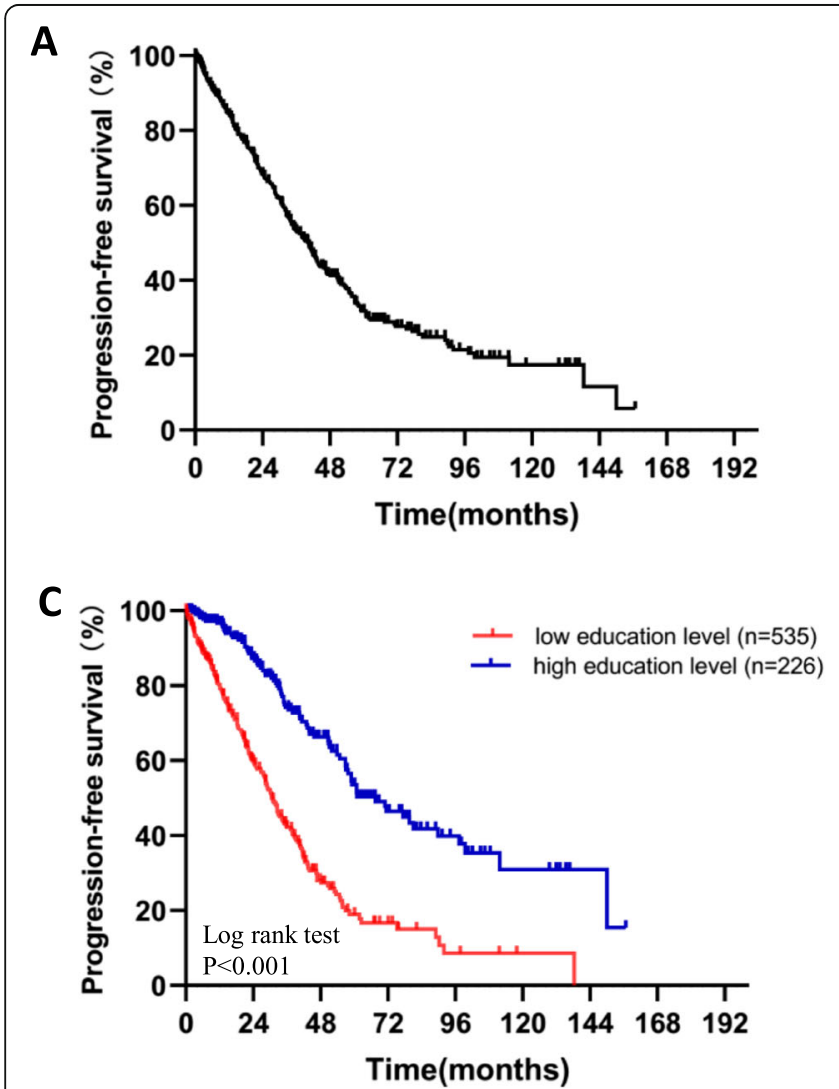

B
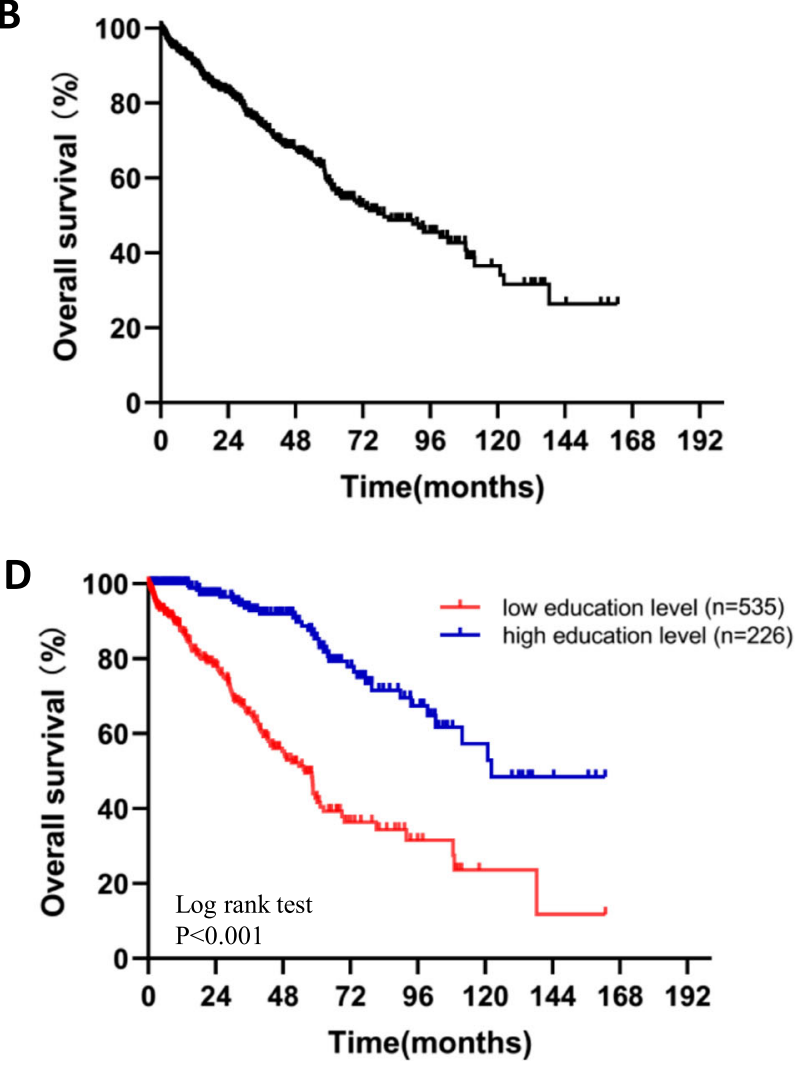

Fig. 1 Kaplan-Meier plots of PFS and OS for MM patients. a The median PFS for 773 MM patients. b The median OS for 773 MM patients. c Kaplan-Meier plots of PFS were compared between MM patients with high and low education levels. $\mathbf{d}$ Kaplan-Meier plots of OS were compared between MM patients with high and low education levels 
Table 3 Univariate analysis of the baseline parameters associated with PFS and OS

\begin{tabular}{|c|c|c|c|c|}
\hline \multirow[t]{2}{*}{ Variable } & \multicolumn{2}{|l|}{ PFS } & \multicolumn{2}{|l|}{ OS } \\
\hline & $\mathrm{HR}(95 \% \mathrm{Cl})$ & $P$ & $\mathrm{HR}(95 \% \mathrm{Cl})$ & $P$ \\
\hline \multicolumn{5}{|l|}{ Sex } \\
\hline Male vs female & $1.04(0.83-1.30)$ & 0.74 & $0.97(0.73-1.29)$ & 0.823 \\
\hline Age (per year of age) & $1.03(1.02-1.04)$ & $<0.001$ & $1.04(1.02-1.05)$ & $<0.001$ \\
\hline \multicolumn{5}{|l|}{ Smoking } \\
\hline Yes vs no & $0.95(0.74-1.23)$ & 0.71 & $0.93(0.68-1.29)$ & 0.671 \\
\hline \multicolumn{5}{|l|}{ Marital status } \\
\hline Married vs other & $0.78(0.44-1.34)$ & 0.41 & $0.85(0.40-1.81)$ & 0.672 \\
\hline \multicolumn{5}{|l|}{ Residential area } \\
\hline Rural vs urban & $1.48(1.14-1.93)$ & 0.003 & $1.47(1.06-2.05)$ & 0.023 \\
\hline \multicolumn{5}{|l|}{ Distance to hospital } \\
\hline Different province vs the same province & $1.18(1.01-1.37)$ & 0.039 & $1.15(0.94-1.41)$ & 0.175 \\
\hline \multicolumn{5}{|l|}{ Education level } \\
\hline High vs low education level & $0.39(0.30-0.52)$ & $<0.001$ & $0.25(0.17-0.38)$ & $<0.001$ \\
\hline \multicolumn{5}{|l|}{ Occupational status } \\
\hline Unemployed vs employed & $1.67(1.22-2.30)$ & 0.002 & $2.53(1.55-4.13)$ & $<0.001$ \\
\hline \multicolumn{5}{|l|}{ Average annual income } \\
\hline$\geq \$ 42,500$ vs $<\$ 42,500$ USD & $0.51(0.37-0.70)$ & $<0.001$ & $0.36(0.23-0.55)$ & $<0.001$ \\
\hline \multicolumn{5}{|l|}{ Insurance status } \\
\hline No insurance vs any insurance & $1.54(1.15-2.06)$ & 0.004 & $2.16(1.43-3.29)$ & $<0.001$ \\
\hline \multicolumn{5}{|l|}{ Comorbidity } \\
\hline Yes vs no & $1.72(1.35-2.18)$ & $<0.001$ & $2.54(1.81-3.56)$ & $<0.001$ \\
\hline \multicolumn{5}{|l|}{ Time to diagnosis } \\
\hline$>1$ vs $\leq 1$ month & $1.47(1.13-1.91)$ & 0.004 & $1.96(1.37-2.81)$ & $<0.001$ \\
\hline \multicolumn{5}{|l|}{ ISS stage } \\
\hline III vs $|/| \mid$ & $1.23(1.09-1.39)$ & 0.001 & $1.38(1.19-1.60)$ & $<0.001$ \\
\hline \multicolumn{5}{|l|}{ LDH level } \\
\hline$\geq 240 \mathrm{vs}<240 \mathrm{U} / \mathrm{L}$ & $1.87(1.43-2.46)$ & $<0.001$ & $1.85(1.32-2.60)$ & $<0.001$ \\
\hline \multicolumn{5}{|l|}{ Cytogenetics } \\
\hline High risk vs standard risk & $1.68(1.26-2.25)$ & $<0.001$ & $1.98(1.38-2.82)$ & $<0.001$ \\
\hline \multicolumn{5}{|l|}{ Receipt of transplant } \\
\hline No vs yes & $2.98(2.34-3.80)$ & $<0.001$ & $2.53(1.87-3.44)$ & $<0.001$ \\
\hline \multicolumn{5}{|l|}{ Regular treatment } \\
\hline no vs yes & $3.28(2.59-4.16)$ & $<0.001$ & $3.51(2.61-4.71)$ & $<0.001$ \\
\hline
\end{tabular}

PFS progression-free survival, OS overall survival, HR hazard ratio, Cl confidence interval, ISS international staging system, LDH lactate dehydrogenase

educational level of these patients have an interactive effect on survival, we conducted a hierarchical analysis of age. The results of multivariate Cox regression analyses showed that education level was an independent factor affecting the prognosis of MM patients after adjustments were made for potential confounders. Our results showed that patients with high education levels were more likely to have a longer PFS and OS. Patients with high education levels were younger, and the time from onset of symptoms to diagnosis was shorter. Those factors may result in patients in this subgroup having lower tumor loads (e.g., LDH levels and ISS stages) and fewer complications. In addition, patients with high education levels were more likely to choose effective treatments, such as transplantation, than patients with low education levels, and these patients more often received regular treatment. Therefore, the above factors may partly explain why education levels affect patient survival.

In addition, our results showed that patients with high education levels have financial and work support, and 
Table 4 Multivariate analysis of baseline parameters associated with PFS

\begin{tabular}{lll}
\hline Variables & PFS & \\
\cline { 2 - 3 } & HR $(95 \% \mathrm{Cl})$ & $P$ \\
\hline All patients & $0.50(0.34-0.72)$ & $<0.001$ \\
Education level: high vs low & $2.08(1.48-2.94)$ & $<0.001$ \\
LDH: $\geq 240$ vs < 240 U/L & $1.77(1.28-2.45)$ & 0.001 \\
Cytogenetics: high risk vs standard risk & $2.70(1.95-3.74)$ & $<0.001$ \\
Receipt of transplant: no vs yes & & \\
Patients < 60 years & $0.47(0.29-0.74)$ & 0.002 \\
Education level: high vs low & $2.45(1.52-3.95)$ & 0.001 \\
LDH: $\geq 240$ vs < 240 U/L & $1.85(1.18-2.90)$ & 0.007 \\
Cytogenetics: high risk vs standard risk & $2.00(1.20-3.35)$ & 0.008 \\
Receipt of transplant: no vs yes & $2.08(1.53-3.73)$ & 0.015 \\
Regular treatment: no vs yes & & \\
Patients $\geq 60$ years & $0.53(0.29-0.98)$ & 0.043 \\
Education level: high vs low & $1.81(1.10-3.00)$ & 0.020 \\
LDH: $\geq 240$ vs < 240 U/L & $1.68(1.03-2.72)$ & 0.037 \\
Cytogenetics: high risk vs standard risk & $2.38(1.36-4.17)$ & 0.002 \\
\hline Receipt of transplant: no vs yes & & \\
\hline
\end{tabular}

PFS progression-free survival, $H R$ hazard ratio, $\mathrm{Cl}$ confidence interval, $L D H$ lactate dehydrogenase

Table 5 Multivariate analysis of baseline parameters associated with OS

\begin{tabular}{lll}
\hline Variables & OS & \\
\cline { 3 - 3 } & HR (95\% Cl) & $P$ \\
\hline All patients & $1.03(1.00-1.05)$ & 0.028 \\
Age (per year of age) & $0.32(0.19-0.56)$ & $<0.001$ \\
Education level: high vs low & $1.86(1.18-2.94)$ & 0.008 \\
LDH: $\geq 240$ vs < 240 U/L & $2.01(1.32-3.06)$ & 0.001 \\
Cytogenetics: high risk vs standard risk & $2.01(1.25-3.23)$ & 0.004 \\
Comorbidity: yes vs no & $1.73(1.08-2.77)$ & 0.024 \\
Regular treatment: no vs yes & & \\
Patients < 60 years & $0.30(0.14-0.62)$ & 0.001 \\
Education level: high vs low & $2.37(1.30-4.32)$ & 0.005 \\
Cytogenetics: high risk vs standard risk & $2.17(1.08-4.38)$ & 0.030 \\
Regular treatment: no vs yes & & \\
Patients $\geq 60$ years & $0.26(0.11-0.62)$ & 0.002 \\
Education level: high vs low & $2.27(1.24-4.18)$ & 0.008 \\
LDH: $\geq 240$ vs < 240 U/L & $1.84(1.01-3.33)$ & 0.045 \\
Cytogenetics: high risk vs standard risk & $3.16(1.32-7.55)$ & 0.010 \\
\hline Comorbidity: yes vs no &
\end{tabular}

$O S$ overall survival, $H R$ hazard ratio, $C l$ confidence interval, $L D H$ lactate dehydrogenase they tend to have more stable employment and income. These factors may allow them to make treatment choices without cost restrictions and pay more attention to the efficacy of drugs so as to choose a more positive and effective treatment. Similarly, Alter, D.A. et al. reported that compared to patients with lower SES, more affluent or better educated patients were more likely to undergo active and effective treatment [26]. Additionally, insurance is also a very important economic factor, and we found that patients with high education levels are more likely to have insurance coverage. Several studies have reported that insurance status was associated with OS, and patients who were uninsured had poorer survival than those who were insured $[7,27,28]$.

However, for patients with malignant tumors, the mechanism of the impact of education level on their survival is extremely complex. Linder, G. et al. found that high education levels were associated with a greater probability of being offered curative treatment and improved survival in esophageal and gastroesophageal junctional cancer in Sweden; the reason may be communication difficulties and a lack of understanding of treatment, which were more commonly reported in groups with low education levels [29]. This finding reflects that a high level of education can help patients gain a full understanding of their diseases and make it easier to acquire health-related knowledge. Additionally, our study showed that patient education levels were related to treatment compliance, and there was also one report showed that patients with a high education level have better treatment compliance [30]. Besides, some studies have shown that low education levels might undermine the patient's initiative to seek healthcare services, leading to a delay in the diagnosis of a primary disease or a lifethreatening complication [31, 32]. These factors also need to be fully taken into account.

Moreover, patient treatment can be managed according to their SES. At present, new drugs (such as bortezomib and lenalidomide) and ASCT can significantly improve survival in patients with $M M$, but these methods result in a great increase in the cost of treatment [33]. Therefore, drug-induced sequential ASCT is preferred for patients with high SES who are suitable for transplantation, and new drugs are preferred for patients with high SES who are not suitable for transplantation, while patients with low SES can choose less expensive options, such as regimens containing thalidomide combined with cyclophosphamide and dexamethasone. Palliative treatment is more suitable for patients with severe complications who cannot tolerate chemotherapy than for patients with low SES.

Our research has some limitations owing to its retrospective nature. In addition, some of the values were missing, but the proportion of missing values for most 
variables was less than $10 \%$. In addition, we did not get the specific treatment details of these patients and there were many confounding variables in this study. In the future, we can further analyze the relationship between the specific treatment regimens, treatment response, comorbidities and educational levels and survival prognosis.

\section{Conclusions}

With continuous advancements in the treatment of multiple myeloma, the prognosis of patients has greatly improved. However, not all patients benefit equally. By analyzing the relationship between sociodemographic factors and the survival of patients with multiple myeloma in China, we found that education level is an independent factor affecting survival outcomes. In particular, MM patients with high education levels have a better economic foundation, can seek medical treatment in a more timely manner, can choose the best treatment regimens and can be treated more regularly. Therefore, the results of this study indicate that we can use the education level of newly diagnosed patients to evaluate the prognosis of these patients and to create more reasonable treatment plans.

\section{Abbreviations}

MM: Multiple myeloma; ISS: International staging system; LDH: Lactate dehydrogenase; PFS: Progression-free survival; OS: Overall survival;

SES: Socioeconomic status; HR: Hazard ratio; 95\% Cl: 95\%confidence interval; FISH: Fluorescence in situ hybridization

\section{Acknowledgments}

This work was supported by Sun Yat-sen University medical clinical trial "5010 Plan" 2017005.

\section{Authors' contributions}

$J L$ came up with the study concept and design and was involved in editing and review. LX collected the data, prepared and edited the manuscript and performed statistical analysis. XW, XP, XW, QW, BW, JC, YZ, LC, and WL assisted with data acquisition. All authors read and approved of the final manuscript.

\section{Funding}

Not Applicable.

\section{Availability of data and materials}

The datasets generated and/or analysed during the current study are not publicly available as presently we have not been granted permission by the institutional review board to do so. However, data can be made available from the corresponding author on reasonable request.

\section{Ethics approval and consent to participate}

This study was reviewed and approved by the first affiliated hospital of Sun Yat-sen university (IRB:[2019]341). Due to retrospective design of the study, the requirement for informed consent was waived.

\section{Consent for publication}

Not applicable.

\section{Competing interests}

The authors declare that they have no competing interests.

\section{Author details}

'Department of Hematology, The First Affiliated Hospital of Sun Yat-sen University, Guangzhou, Guangdong, China. ${ }^{2}$ Department of Hematology, Sun Yat-Sen Memorial Hospital of Sun Yat-Sen University, Guangzhou, Guangdong, China. ${ }^{3}$ Department of Hematology, The First Affiliated Hospital of Guangdong Pharmaceutical University, Guangzhou, Guangdong, China. ${ }^{4}$ Department of Hematology, The Second Affiliated Hospital of Guilin Medical University, Guilin, Guangxi, China. ${ }^{5}$ Department of Hematology, Guizhou Provincial People's Hospital, Guiyang, Guizhou, China. ${ }^{6}$ Department of Hematology, Shunde Hospital of Southern Medical University, Shunde, Guangdong, China. 'Department of Hematology, First People's Hospital of Foshan, Foshan, Guangdong, China. ${ }^{8}$ Department of Hematology, The First Affiliated Hospital With Nanjing Medical University, Nanjing, Jiangsu, China. ${ }^{9}$ Department of Internal Medicine, Jiangxi Tumor Hospital, Nanchang, Jiangxi, China.

Received: 14 March 2020 Accepted: 13 July 2020

Published online: 08 August 2020

\section{References}

1. Kumar SK, Rajkumar V, Kyle RA, et al. Multiple myeloma. Nat Rev Dis Primers. 2017;3:17046.

2. Rollig C, Knop S, Bornhauser M. Multiple myeloma. Lancet. 2015;385(9983): 2197-208.

3. Tan D, Chng WJ, Chou T, et al. Management of multiple myeloma in Asia: resource-stratified guidelines. Lancet Oncol. 2013;14(12):e571-81.

4. Siegel RL, Miller KD, Jemal A. Cancer statistics, 2019. CA Cancer J Clin. 2019; 69(1):7-34.

5. Ailawadhi S, Bhatia K, Aulakh S, et al. Equal treatment and outcomes for everyone with multiple myeloma: are we there yet? Curr Hematol Malig Rep. 2017;12(4):309-16.

6. Fakhri B, Fiala MA, Tuchman SA, et al. Undertreatment of older patients with newly diagnosed multiple myeloma in the era of novel therapies. Clin Lymphoma Myeloma Leuk. 2018;18(3):219-24.

7. Costa LJ, Brill IK, Brown EE. Impact of marital status, insurance status, income, and race/ethnicity on the survival of younger patients diagnosed with multiple myeloma in the United States. Cancer. 2016; 122(20):3183-90.

8. Fiala MA, Finney JD, Liu J, et al. Socioeconomic status is independently associated with overall survival in patients with multiple myeloma. Leuk Lymphoma. 2015;56(9):2643-9.

9. Kristinsson SY, Derolf AR, Edgren G, et al. Socioeconomic differences in patient survival are increasing for acute myeloid leukemia and multiple myeloma in Sweden. J Clin Oncol. 2009;27(12):2073-80.

10. Chan H, Milne RJ. Impact of age, sex, ethnicity, socio-economic deprivation and novel pharmaceuticals on the overall survival of patients with multiple myeloma in New Zealand. Br J Haematol. 2020;188(5):692-700.

11. Hong S, Rybicki L, Abounader D, et al. Association of Socioeconomic Status with outcomes of autologous hematopoietic cell transplantation for multiple myeloma. Biol Blood Marrow Transplant. 2016;22(6):1141-4.

12. Ailawadhi $S$, Jacobus $S$, Sexton $R$, et al. Disease and outcome disparities in multiple myeloma: exploring the role of race/ethnicity in the cooperative group clinical trials. Blood Cancer J. 2018;8(7):67.

13. Ganguly S, Mailankody S, Ailawadhi S. Many shades of disparities in myeloma care. Am Soc Clin Oncol Educ Book. 2019;39:519-29.

14. Goldstein DA, Clark J, Tu Y, et al. A global comparison of the cost of patented cancer drugs in relation to global differences in wealth. Oncotarget. 2017:8(42):71548-55.

15. Liu W, Liu J, Song Y, et al. Mortality of lymphoma and myeloma in China, 2004-2017: an observational study. J Hematol Oncol. 2019;12(1):22.

16. Rajkumar SV, Dimopoulos MA, Palumbo A, et al. International myeloma working group updated criteria for the diagnosis of multiple myeloma. Lancet Oncol. 2014;15(12):e538-48.

17. Durie $B G$, Harousseau JL, Miguel JS, et al. International uniform response criteria for multiple myeloma. Leukemia. 2006;20(9):1467-73.

18. Palumbo A, Avet-Loiseau H, Oliva S, et al. Revised international staging system for multiple myeloma: a report from international myeloma working group. J Clin Oncol. 2015;33(26):2863-9.

19. Chng WJ, Dispenzieri A, Chim CS, et al. IMWG consensus on risk stratification in multiple myeloma. Leukemia. 2014;28(2):269-77. 
20. Dhakal B, Szabo A, Chhabra S, et al. Autologous transplantation for newly diagnosed multiple myeloma in the era of novel agent induction: a systematic review and meta-analysis. JAMA Oncol. 2018;4(3):343-50.

21. Stringhini S, Carmeli C, Jokela M, et al. Socioeconomic status and the $25 \mathrm{x}$ 25 risk factors as determinants of premature mortality: a multicohort study and meta-analysis of 1.7 million men and women. Lancet. 2017;389(10075): 1229-37.

22. Gray PJ, Lin CC, Cooperberg MR, et al. Temporal trends and the impact of race, insurance, and socioeconomic status in the Management of Localized Prostate Cancer. Eur Urol. 2017;71(5):729-37.

23. Albano JD, Ward E, Jemal A, et al. Cancer mortality in the United States by education level and race. J Natl Cancer Inst. 2007;99(18):1384-94.

24. Attalla K, Paulucci DJ, Blum K, et al. Demographic and socioeconomic predictors of treatment delays, pathologic stage, and survival among patients with penile cancer: A report from the National Cancer Database. Urol Oncol. 2018;36(1):14.e17-24.

25. Hwang KT, Noh W, Cho SH, et al. Education level is a strong prognosticator in the subgroup aged more than 50 years regardless of the molecular subtype of breast Cancer: a study based on the Nationwide Korean breast Cancer registry database. Cancer Res Treat. 2017;49(4):1114-26.

26. Alter DA, Iron $\mathrm{K}$, Austin $\mathrm{PC}$, et al. Socioeconomic status, service patterns, and perceptions of care among survivors of acute myocardial infarction in Canada. JAMA. 2004;291(9):1100-7.

27. Perry AM, Brunner AM, Zou T, et al. Association between insurance status at diagnosis and overall survival in chronic myeloid leukemia: a populationbased study. Cancer. 2017;123(13):2561-9.

28. Walker GV, Grant SR, Guadagnolo BA, et al. Disparities in stage at diagnosis, treatment, and survival in nonelderly adult patients with cancer according to insurance status. J Clin Oncol. 2014;32(28):3118-25.

29. Linder G, Sandin F, Johansson J, et al. Patient education-level affects treatment allocation and prognosis in esophageal- and gastroesophageal junctional cancer in Sweden. Cancer Epidemiol. 2018;52:91-8.

30. Li BD, Brown WA, Ampil FL, et al. Patient compliance is critical for equivalent clinical outcomes for breast cancer treated by breastconservation therapy. Ann Surg. 2000;231(6):883-9.

31. Quaglia A, Lillini R, Mamo C, et al. Socio-economic inequalities: a review of methodological issues and the relationships with cancer survival. Crit Rev Oncol Hematol. 2013;85(3):266-77.

32. Biasoli I, Castro N, Delamain M, et al. Lower socioeconomic status is independently associated with shorter survival in Hodgkin lymphoma patients-an analysis from the Brazilian Hodgkin lymphoma registry. Int J Cancer. 2018;142(5):883-90.

33. Attal M, Lauwers-Cances V, Hulin C, et al. Lenalidomide, Bortezomib, and dexamethasone with transplantation for myeloma. N Engl J Med. 2017; 376(14):1311-20.

\section{Publisher's Note}

Springer Nature remains neutral with regard to jurisdictional claims in published maps and institutional affiliations.

\section{Ready to submit your research? Choose BMC and benefit from:}

- fast, convenient online submission

- thorough peer review by experienced researchers in your field

- rapid publication on acceptance

- support for research data, including large and complex data types

- gold Open Access which fosters wider collaboration and increased citations

- maximum visibility for your research: over $100 \mathrm{M}$ website views per year

At BMC, research is always in progress.

Learn more biomedcentral.com/submissions 